\title{
A Double-Blind, Placebo-Controlled Trial to Evaluate the Safety, Tolerability, and Pharmacokinetics of Single, Escalating Oral Doses of JDTic
}

\author{
Jeffrey J Buda', FI Carroll ${ }^{2}$, Thomas R Kosten ${ }^{3}$, Dennis Swearingen ${ }^{4}$ and Bradford B Walters ${ }^{*, 2}$ \\ 'RTI Health Solutions, Research Triangle Park, NC, USA; ${ }^{2}$ RTI International, Research Triangle Park, NC, USA; ${ }^{3}$ Department of Psychiatry and \\ Behavioral Sciences, Baylor College of Medicine, Houston, TX, USA; ${ }^{4}$ Celerion, Tempe, AZ, USA
}

\begin{abstract}
Animal studies suggest that kappa opioid receptor antagonists (KORAn) potentially could treat a wide variety of addictive and depressive disorders. We assessed the KORAn JDTic for safety, tolerability, and pharmacokinetics in a double-blind, placebo-controlled, randomized trial evaluating single oral doses in healthy adult males. Predose and postdose safety assessments included orthostatic vital signs; 6-lead continuous telemetry monitoring (approximately $16 \mathrm{~h}$ predose to $24 \mathrm{~h}$ postdose); 12 -lead electrocardiograms (ECGs); clinical chemistry, hematology, coagulation, and urinalysis; psychomotor functioning (using the Wayne Saccadic Fixator (WSF)); and adverse events. As a potential indicator of JDTic effects on affect, the POMS Standard instrument was administered predose and daily postdose Days I-6. At I mg, 2 of the 6 JDTic (and 0/6 placebo) subjects experienced a single, asymptomatic event of multiple beats of nonsustained ventricular tachycardia (NSVT). Their events were temporally similar with respect to time postdose (and the postdose timing of an NSVT event in a monkey). These events triggered a study stopping rule. No differences were observed between the placebo and JDTic subjects with respect to clinical chemistry, hematology, coagulation, urinalysis, orthostatic vital signs, WSF, or I2-lead ECG parameters. Plasma JDTic levels were below the lower limit of quantitation $(0.1 \mathrm{nM})$ in all subjects. There were no significant differences in POMS scores between the placebo and JDTic groups. Although the evidence is circumstantial, it suggests that NSVT is a potential JDTic toxicity in humans. Given the therapeutic potential of KORAn, further investigation is needed to determine whether a significant JDTic human cardiac effect indeed exists, and if so, whether it is specific to JDTic or represents a KORAn class effect.
\end{abstract}

Neuropsychopharmacology (20I5) 40, 2059-2065; doi:I0.1038/npp.20I5.27; published online 4 March 2015

\section{INTRODUCTION}

The kappa opioid receptor (KOR) and its endogenous ligand dynorphin are enriched in brain regions involved in stress response, and potential clinical utility for KOR antagonists (KORAn) has been shown in depression and substance abuse (Carroll and Carlezon, 2013). JDTic is a potent and selective KORAn (Thomas et al, 2003) that in preclinical models shows antidepressant and anxiolytic activity and reduces the signs of nicotine withdrawal, the stress-induced reinstatement of cocaine-reinforced behavior, and manifestations of alcohol abuse (Carroll and Dolle, 2014). KORAn are a drug class of considerable pharmaceutical interest, and RTI International intended to develop JDTic for several indications. This article reports the results of the first-in-human safety study.

Kappa-active compounds also have cardiovascular effects; however, results are mixed. In most rat studies, kappa

*Correspondence: Dr BB Walters, RTI International, 3040 E. Cornwallis Road, P.O. Box 12194, Research Triangle Park, NC 27709-2154, USA, Tel: + I 919316 3509, Fax: + I 919 54I 1275, E-mail: bwalters@rti.org Received 2 August 20 14; revised I 4 January 20 I5; accepted 16 January 2015; accepted article preview online 23 January 2015 opioid receptor agonists (KORAg) are cardioprotective (eg, Jaiswal et al, 2010; Zhou et al, 2001), reduce arrhythmias (eg, Jin-Cheng et al, 2008; Lishmanov et al, 2007; Peart et al, 2004; Xiu et al, 2013), have positive inotropic effects (eg, Pyle et al., 2001), and are a component of ischemic preconditioning (Yu et al, 1999; Zatta et al, 2008). Consequently, KORAn could have negative effects. One study reported that highly selective KORAn activate c-Jun $\mathrm{N}$-terminal kinase (JNK; Bruchas et al, 2007). In another study, lipopolysaccharide activation of JNK caused disruption of fatty acid oxidation by a human ventricular-derived cardiomyocyte cell line and caused cardiac dysfunction in C57BL/6 mice (Drosatos et al, 2011). However, in dogs (Hartlage et al, 2006) and swine (Coles et al, 2003), KORAn are cardioprotective. Also, negative inotropic (Ventura et al, 1992) and pro-arrhythmic (Bian et al, 1998) effects of U-50,488 H and cardioprotective effects of nor-BNI (Liu et al, 2005) are described in rats.

Biopsied human ventricular myocytes contain dynorphin (Ationu et al, 1993), and surgical specimens of human atrial tissue (Lendeckel et al, 2005) and pooled human heart extracts (Peng et al, 2012) contain KOR mRNA. In human hearts, there are KOR immunoreactive fine nerve fibers, cardiomyocytes, and cells resembling intrinsic 
cardiac adrenergic cells (Sobanski et al, 2014), consistent with rabbit cardiomyocyte immunoprecipitation studies (Surendra et al, 2013). The KORAg U-50,488H has negative inotropic effects on isolated human right atrial strips not antagonized by the selective KORAn nor-BNI or the broader-acting naloxone (Llobell and Laorden, 1995). Similarly, U-50,488H has effects on transient outward $\mathrm{K}^{+}$and ultrarapid delayed rectifier $\mathrm{K}^{+}$currents in human pediatric atrial myocytes that are not antagonized by nor-BNI or naloxone (Xiao et al, 2003). However, in human subjects undergoing angioplasty, the acute ischemic preconditioning effect of the first of a pair of balloon occlusions was abolished by naloxone (Tomai et al, 1999). Ventricular tachycardia is listed under 'Precautions' and 'Adverse Reactions' in the product insert for naloxone (Hospira, 2007) and is described in case reports (eg, Hunter, 2005). In the first-in-human study of the KORAn LY2456302 (Lowe et al, 2014, p. 6), 'a 5-beat ventricular tachycardia occurring approximately $8 \mathrm{~h}$ after receiving a single $25-\mathrm{mg}$ dose' was observed in 1 of the 21 subjects (5\%) receiving the drug, which does not activate JNK (Melief et al, 2011).

Nonclinical studies (data on file, RTI International, Research Triangle Park, NC) identified potential JDTic electrocardiogram (ECG) toxicities but at a human equivalent dose (HED) of $>6000 \mathrm{mg}$ and plasma concentrations $>920 \mathrm{nM}$. Review of the first $24 \mathrm{~h}$ of ECG following a $200 \mathrm{mg} / \mathrm{kg}$ intragastric dose of JDTic (HED of $4500 \mathrm{mg}$ ) revealed one of the six cynomolgus monkeys (17\%) had three ventricular premature complexes in a row (by definition, nonsustained ventricular tachycardia (NSVT)), at $11 \mathrm{~h} 51 \mathrm{~min}$ postdose (Figure 1a). NSVT in cynomolgus monkeys can be an incidental finding; 16- to 24-h Holter monitoring of a colony of 62 monkeys revealed ventricular tachycardia (VT) in 8 (13\%) (Macallum and Houston, 1993). Asymptomatic NSVT can be observed in humans (cf. Min et al, 2010). NSVT prevalence in normal, healthy males is described in four publications using qualitatively different populations (eg, inclusion of females, significantly higher median age), with estimates in the range of $2-3.2 \%$ (Bjerregaard, 1982; Brodsky et al, 1977; Clarke et al, 1976; Hinkle et al, 1969).

Following the human trial, a preliminary analysis of JDTic effects in human iPSC cardiomyocyte cultures (approach described by Guo et al, 2011) estimated that the concentration at which $>20 \%$ of the spontaneous beats were arrhythmic was between 2 and $20 \mathrm{nM}$ (Supplementary Figure S1). These concentrations are well below the $\mathrm{IC}_{50}$ values observed for hERG channel, human cardiac sodium channel, and guinea pig L-type calcium channel (5000 nM) (data on file, RTI).

\section{SUBJECTS AND METHODS}

\section{Study Design}

The JDTic-001 study was a single-center, double-blind, placebo-controlled, randomized clinical trial to evaluate the safety, tolerability, and pharmacokinetics (PK) of single, escalating oral doses of JDTic $(1,3$, and $10 \mathrm{mg})$ in healthy male subjects, in three separate cohorts using a semiadap-
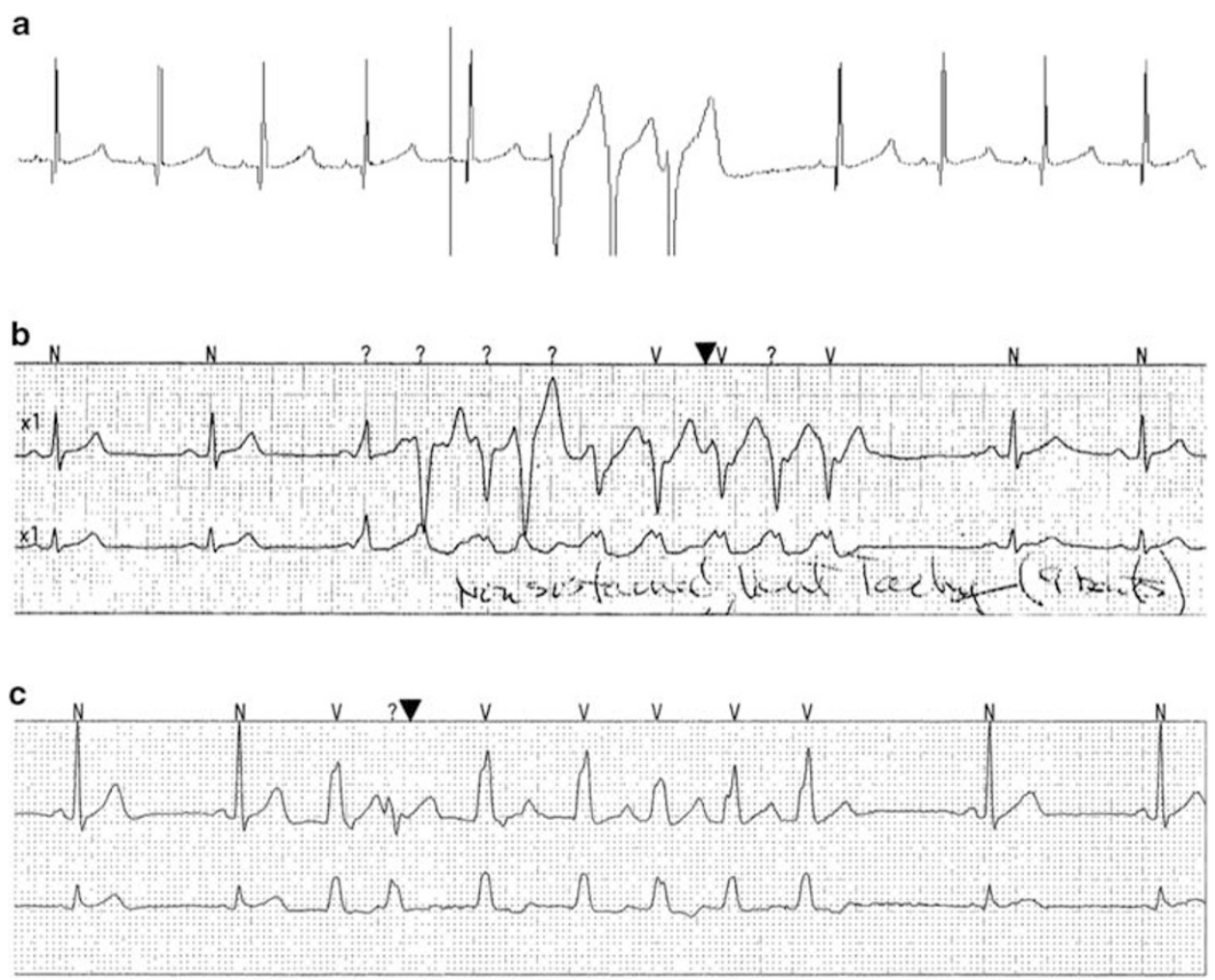

Figure I Nonsustained ventricular tachycardia (NSVT) in preclinical and clinical subjects. (a) 3-Beat NSVT in male cynomolgus monkey II.8 h after $200 \mathrm{mg} / \mathrm{kg}$ intragastric JDTic (timescale not available). (b) 9-Beat NSVT in male human subject $13.5 \mathrm{~h}$ after I mg oral JDTic (the smallest grid boxes represent 0.04 s). (c) 7-Beat NSVT in male human subject $11.5 \mathrm{~h}$ after I $\mathrm{mg}$ oral JDTic (same timescale as in panel (b)). 
tive dosing plan (cohorts 1 and 2 comprised four subjects and cohort 3 comprised eight subjects, in each case randomized 3:1 JDTic:placebo). Prior to dosing a subsequent cohort, all safety and PK data were reviewed by a Safety Review Team (SRT) as guided by a Data and Safety Monitoring Plan (DSMP). If adverse events (AEs) considered to be at least possibly related to study medication occurred during the first two cohorts, an additional four subjects were dosed at that same dose level, unless otherwise determined by the SRT. A final amendment put in place after the initial eight subjects were dosed stipulated that if AEs requiring study termination occurred during an eight-subject cohort, an additional four blinded subjects would be dosed with placebo; consequently, this portion is single blind.

DSMP stopping rules included typical criteria for serious adverse events (SAEs) and adverse events of specific interest (AESI) (eg, terminating the study if $\geqslant 25 \%$ of a dosing cohort experienced a possibly or definitely drug-related AESI, such as NSVT), as well as limitations on JDTic plasma maximum concentration $\left(C_{\max }\right)$ and area under the curve from zero to infinity $\left(\mathrm{AUC}_{0-\infty}\right)$. The starting dose in the trial, $1 \mathrm{mg}$, was predicted to result in a maximum plasma concentration of $0.04 \mathrm{nM}$ (below the lower level of quantitation, $0.1 \mathrm{nM}$ ); this was reduced from a proposed $3 \mathrm{mg}$ starting dose, in response to a Food and Drug Administration clinical hold. Also in response, protocol ECG exclusion criteria were made even more restrictive than normal (eg, PR interval >180 ms, QTcB interval >420 ms), and telemetry was expanded to begin the night before dosing and to continue for $24 \mathrm{~h}$ postdose.

Potential subjects presented to the clinic within 14 days of their intended dose date to undergo a battery of screening assessments. Eligible subjects came to the clinic the day before dosing for eligibility reconfirmation. Subjects remained in the clinic that night and for 6 days postdose for safety assessments and timed blood and urine collections. If there were no ongoing safety issues on Day 6, subjects were sent home from the clinic and they returned 14 days later for a follow-up safety assessment. Subjects were then discharged from the study.

This study was approved by the clinical site's Institutional Review Board and conducted in accordance with the International Conference on Harmonisation E6 Consolidated Guidance for Good Clinical Practice (1996), the US Code of Federal Regulations 21 parts 50 and 56, and the ethical principles of the Declaration of Helsinki (as amended in 1996). It was performed at Celerion in Tempe, $\mathrm{AZ}$, and is reported at ClinicalTrials.gov (NCT01431586).

\section{Participants}

Inclusion criteria. Subjects were healthy males, $18-50$ years, $\geqslant 50 \mathrm{~kg}$ in weight, body mass index (BMI) $18-30 \mathrm{~kg} / \mathrm{m}^{2}$, with normal vital signs (heart rate, systolic and diastolic blood pressure, respiratory rate, oral temperature), a negative prestudy drug screen (alcohol, cannabinoids, amphetamines, benzodiazepines, cocaine, opioids, phencyclidine, barbiturates, cotinine), no history of use of illicit drugs or other substances of abuse within 12 months of the screening visit, no tobacco use for $\geqslant 90$ days prior to screening, and no history of cardiovascular disease. Routine 12-lead ECG at screening (a 10-s single-lead rhythm strip and approximately 2.5-s samples of each lead) had to be without clinically significant abnormalities, as did laboratory analyses of hematology (hemoglobin, hematocrit, reticulocyte count, red blood cells, red blood cell indices, white blood cells, white blood cell differential), chemistry (aspartate aminotransferase, alanine aminotransferase, gamma glutamyl transferase, serum troponin I, blood urea nitrogen, creatinine, total bilirubin, alkaline phosphatase, creatine kinase, lactate dehydrogenase, uric acid, total protein, globulin, cholesterol, triglycerides, sodium, potassium, calcium, chloride, phosphorus), coagulation (prothrombin time, activated partial thromboplastin time), urinalysis (specific gravity, $\mathrm{pH}$, bilirubin, nitrite, urobilinogen, glucose, protein, blood, leukocytes, ketones, microscopic examination), and serology (HIV, hepatitis B surface antigen, hepatitis $\mathrm{C}$ antibodies).

Exclusion criteria. Subjects were excluded for a history or evidence of hepatic, gastrointestinal, renal, respiratory, ophthalmic, cardiovascular, hematological, endocrine/ metabolic, neurological, immunological, oncological, or psychiatric illness or significant abnormalities, or any other conditions or surgical interventions known to interfere with the absorption, distribution, metabolism, or excretion of drugs. Subjects were excluded for any active infection. Consumption of alcohol within $48 \mathrm{~h}$ of screening or clinic admission; of caffeine-containing beverages within $72 \mathrm{~h}$ of clinic admission; or of grapefruit or grapefruit-, poppy seed-, or quinine-containing substances within 14 days of clinic admission were exclusionary. Subjects were excluded for any clinically significant ECG finding prior to dosing (including bundle branch blocks, second- or third-degree heart block, arrhythmia other than respiratory sinus arrhythmia, or multiple premature atrial contractions or premature ventricular contractions but with the exception of nonclinically significant unifocal premature ventricular contractions), presence or history of early cardiac repolarization, or a history or family history of QT prolongation or arrhythmia. ECG parameters outside the following ranges were also exclusionary: heart rate 55-100, PR interval $120-180 \mathrm{~ms}$, QRS duration 70-100 ms, QTcB interval $\leqslant 420 \mathrm{~ms}$.

\section{Safety and Tolerability End Points}

Observational. Orthostatic vital signs were obtained predose and at $1,2,4,6,8,12,24,48,72,96$, and $120 \mathrm{~h}$ postdose, as well as at 14 days postdose follow-up. Body weight was measured on admission to the clinic, at 48 and $120 \mathrm{~h}$ postdose, and at 14 days postdose follow-up. Physical examinations of all major organ systems (including neurological examination) were performed at admission, at $120 \mathrm{~h}$ postdose, and at 14 days postdose follow-up. AEs were monitored from dosing until 14 days postdose or resolution, whichever was longer. Psychomotor function was evaluated with the Wayne Saccadic Fixator (WSF; Wayne Engineering, Skokie, IL) on admission and at $120 \mathrm{~h}$ postdose.

Electrocardiogram. 6-Lead ECG telemetry was monitored from admission (approximately $16 \mathrm{~h}$ predose) until $24 \mathrm{~h}$ postdose. Supine, standard 12-lead ECGs (a 10-s single-lead rhythm strip and approximately 2.5 -s tracings of each lead) 
were obtained predose; at $1,2,4,6,8,12,24,48,72,96$, and $120 \mathrm{~h}$ postdose; and at 14 days postdose follow-up.

Clinical laboratory. Urine for urinalysis and fasted blood samples for chemistry, hematology, and coagulation were obtained on admission, at 48 and $120 \mathrm{~h}$ postdose, and at 14 days postdose follow-up.

\section{Pharmacokinetics}

Blood samples were obtained at $0.25,0.5,1,1.5,2,4,6,8,12$, $16,24,30,36,48,60,72,96$, and $120 \mathrm{~h}$ postdose. Cumulative urine specimens were collected over the intervals $0-6,6-12$, $12-24,24-36,36-48,48-72,72-96$, and $96-120 \mathrm{~h}$ postdose.

\section{Potential Surrogate Marker of Activity}

As a potential indicator of JDTic effects on subject affect, the Profile of Mood States Standard instrument (POMS; Multi-Health Systems, North Tonawanda, NY) was administered (in the 'Right Now' recall period) on admission to the clinic and on Days 1-6 postdose.

\section{RESULTS}

\section{Study Population}

The first subject enrolled on 8 August 2011, and the final subject completed the trial on 12 December 2011. The demographic profile of the study population is summarized in Table 1. All subjects in the study were male. Six (50\%) of the study subjects were of Hispanic ethnicity. The majority (9 of the 12 subjects) were white, 2 were black/African American, and 1 was Asian. Mean age was 31 years (range $19-44$ years) and mean BMI was $25 \mathrm{~kg} / \mathrm{m}^{2}$ (range $22-28 \mathrm{~kg} / \mathrm{m}^{2}$ ).

Table I Summary of Subject Demographics

\begin{tabular}{|c|c|c|c|}
\hline Subject demographics & $\begin{array}{c}\text { Placebo } \\
(n=6)\end{array}$ & $\begin{array}{l}\text { I mg JDTic } \\
(n=6)\end{array}$ & $\begin{array}{l}\text { Overall } \\
(n=12)\end{array}$ \\
\hline \multicolumn{4}{|l|}{ Race, n (\%) } \\
\hline Asian & 0 & I (I7\%) & I (8\%) \\
\hline Black or African American & 0 & $2(33 \%)$ & $2(17 \%)$ \\
\hline White & $6(100 \%)$ & $3(50 \%)$ & $9(75 \%)$ \\
\hline \multicolumn{4}{|l|}{ Ethnicity, n (\%) } \\
\hline Hispanic or Latino & $4(67 \%)$ & $2(33 \%)$ & $6(50 \%)$ \\
\hline Not Hispanic or Latino & $2(33 \%)$ & $4(67 \%)$ & $6(50 \%)$ \\
\hline Age in years, mean (SD) & $27(6)$ & $35(7)$ & $31(8)$ \\
\hline Range & $19-34$ & $22-44$ & $19-44$ \\
\hline Height in cm, mean (SD) & $167(3)$ & $174(5)$ & $170(6)$ \\
\hline Range & $|6|-|7|$ & $169-184$ & $16 \mid-184$ \\
\hline Weight in kg, mean (SD) & 7I (8) & $76(9)$ & $74(9)$ \\
\hline Range & $62-83$ & $61-89$ & $61-89$ \\
\hline $\mathrm{BMI}$ in $\mathrm{kg} / \mathrm{m}^{2}$, mean (SD) & $26(2)$ & $25(2)$ & $25(2)$ \\
\hline Range & $23-28$ & $22-27$ & $22-28$ \\
\hline
\end{tabular}

Abbreviation: BMI, body mass index.
The demographic profiles of those subjects who received JDTic $1 \mathrm{mg}$ and those subjects who received placebo were similar, with the exception of race. All 6 subjects who received placebo were white $v s 3(50 \%)$ of the 6 subjects who received JDTic $1 \mathrm{mg}$.

\section{Safety and Tolerability}

There were no deaths and no SAEs reported during the study, and no AE led to an individual subject discontinuing the study prematurely.

Overall, there were 13 reported AEs: 9 AEs in the subjects who received JDTic $1 \mathrm{mg}$ and $4 \mathrm{AEs}$ in the subjects who received placebo. Four unique subjects exposed to $1 \mathrm{mg}$ JDTic (67\%) and 4 unique subjects who received placebo (67\%) experienced at least one AE (Table 2). Six AEs were considered to be possibly related to the study medication, and four AEs were in three subjects who received JDTic: VT ( 9 beats, $13.5 \mathrm{~h}$ postdose; Figure $1 \mathrm{~b}$ ), bradycardia and VT (7 beats, $11.5 \mathrm{~h}$ postdose; Figure 1c), and postural dizziness. The arrhythmias were asymptomatic and were detected the following mornings via review of the entire telemetry tracings by a cardiologist.

As specified in the JDTic-001 protocol and DSMP, the two instances of NSVT in two subjects after administration of JDTic (a 33\% incidence in subjects receiving JDTic) triggered a study termination rule. Both of these subjects subsequently underwent cardiac evaluations (21-41 days postdose), including echocardiograms, exercise myocardial perfusion studies, and treadmill stress tests. They remained asymptomatic, and no abnormalities were revealed. Protocol Amendment 3 (which allowed for the dosing of four additional subjects with placebo) was drafted to provide additional control subjects to better ascertain a relationship between the occurrence of NSVT and JDTic administration. None of the four additional subjects dosed under Amendment 3 experienced NSVT during the study.

Other safety results were unremarkable: clinical chemistry, hematology, coagulation, urinalysis, orthostatic vital signs, 12-lead ECGs (including heart rate (Figure 2a), PR interval, QRS duration, and QTcB interval (Figure 2b)), and psychomotor functioning. As these figures show, the mean HR and QTcB duration were consistently slower and shorter for JDTic than placebo subjects at all predose and postdose time points, although the differences were not statistically significant $(p>0.05)$.

\section{Pharmacokinetics}

JDTic was not detected in the plasma of any subject (lower limit of quantitation $0.1 \mathrm{nM}$ ).

\section{Potential Surrogate Marker of Activity}

There were no significant differences in POMS scores between the placebo and JDTic groups (Supplementary Table S1).

\section{DISCUSSION}

In this first-in-human clinical trial of the KORAn JDTic, six subjects received the starting oral dose of $1 \mathrm{mg}$ and six 
Table 2 Adverse Events

\begin{tabular}{|c|c|c|c|}
\hline Subject & Adverse event & Clinical principal investigator's assessment of causality & Treatment \\
\hline \multirow[t]{2}{*}{11102} & Ventricular tachycardia ( 9 beats) & Possibly related & I mg JDTic \\
\hline & Presyncope (unrelated to ventricular tachycardia) & Definitely not related & \\
\hline 11103 & Dizziness postural & Possibly related & Placebo \\
\hline \multirow[t]{2}{*}{12101} & Bradycardia & Possibly related & I mg JDTic \\
\hline & Ventricular tachycardia (7 beats) & Possibly related & \\
\hline \multirow{3}{*}{12104} & Vessel puncture site pain & Definitely not related & \\
\hline & Dizziness postural & Possibly related & \\
\hline & Dermatitis contact & Definitely not related & \\
\hline 12105 & Excoriation & Definitely not related & I mg JDTic \\
\hline
\end{tabular}
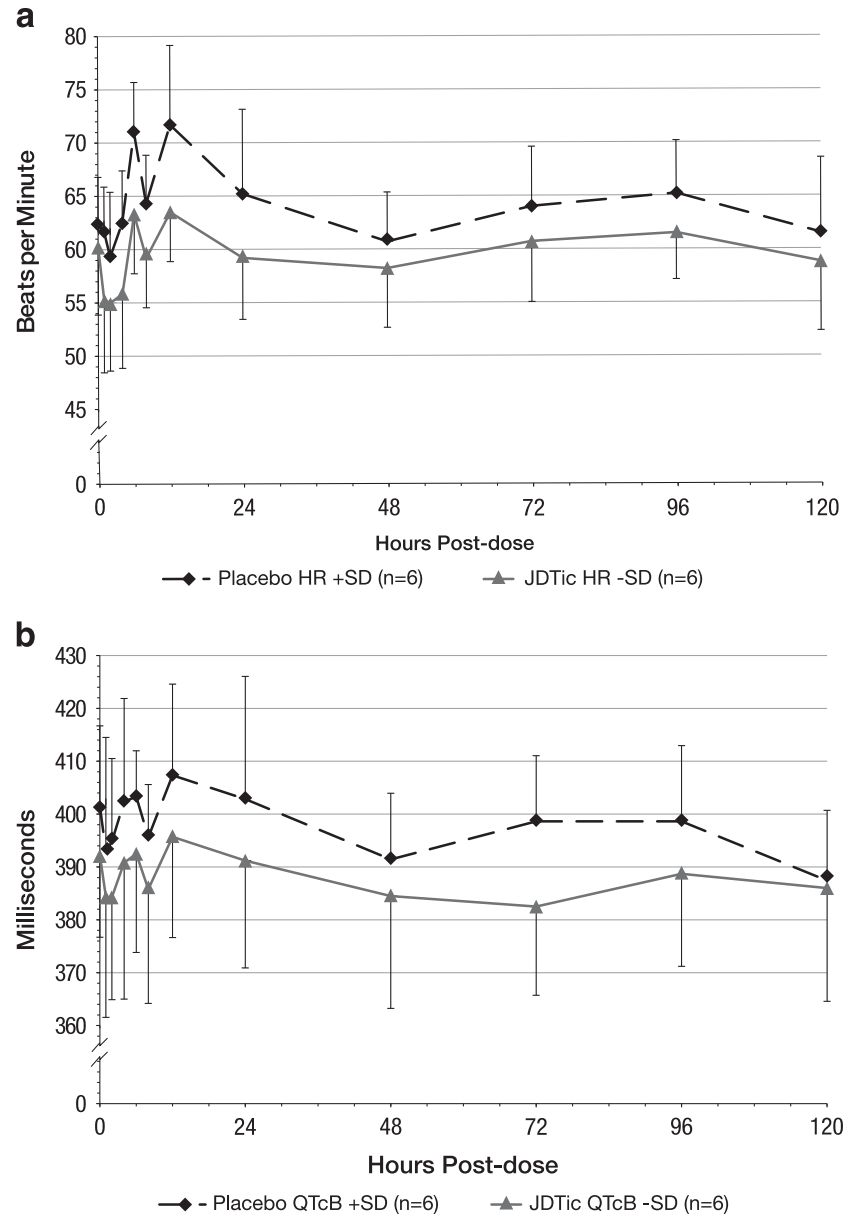

Figure 2 Subject electrocardiogram (ECG) heart rate and QTcB interval over time. (a) ECG heart rate. (b) QTCB interval.

subjects received placebo. JDTic was undetectable in their plasma (LLOQ 0.1 nM). There were no deaths and no SAEs. Subjective AEs possibly related to study drug in placebo subjects were postural dizziness (one instance) and somnolence (one instance). In JDTic subjects, AEs comprised postural dizziness (one instance). There were no significant differences in clinical laboratory parameters (chemistry, hematology, coagulation, urinalysis), 12-lead ECG parameters, or WSF measures of psychomotor function. POMS scores did not differ between placebo and JDTic subjects. However, two JDTic subjects (33\%) had asymptomatic single instances of NSVT on telemetry, triggering a study stopping rule.

We were surprised by the surfacing of a potential NSVT safety signal at the initial $1 \mathrm{mg}$ dose. Applying the published $2-3.2 \%$ prevalence range of NSVT to the study population, the project statistician calculated the probability range of having exactly two otherwise healthy people with NSVT in a random sample of six people to be 0.006-0.013. In terms of study site experience with NSVT prevalence during the previous 9 years, it is estimated that approximately one in 3000 subjects showed an episode of NSVT. This is based on numerous studies which had cardiac rhythm monitoring either as a function of safety telemetry or as a function of thorough QT analysis. However, the full ECG/telemetry/ Holter record was not reviewed by a cardiologist in all of these studies. Nevertheless, these site-specific data imply a very low prevalence.

Although the evidence is circumstantial, based on the temporal similarity of the 2 individual occurrences of NSVT out of 6 subjects (33\%) who received JDTic, the statistical unlikelihood that the 2 observed occurrences of NSVT were preexisting conditions in the affected subjects, the temporal similarity to the episode of NSVT observed in 1 of the $6(17 \%)$ monitored monkeys dosed with JDTic, and the existence of a possible causal mechanism, NSVT could be a JDTic toxicity in humans. Certainly, there is no longer any commercial interest in the clinical development of JDTic.

Given the preclinical and clinical data presented in the Introduction, it is plausible that JDTic could have a direct cardiac interaction in human beings, although perhaps not through the classic KOR, which itself has myriad potential 
cellular interactions (Bruchas and Chavkin, 2010). Although plasma JDTic levels were unquantifiable $(<0.1 \mathrm{nM})$ in this human study, there is preclinical data to suggest that $1 \mathrm{mg}$ could be an efficacious human dose for KOR antagonism. The intragastric JDTic $A D_{50}$ for inhibition of the effects of exogenous enadoline-induced behaviors (15 $\mathrm{min}$ postdose) in cynomolgus monkeys was $0.025 \mathrm{mg} / \mathrm{kg}$, which would equate to an HED of $0.5 \mathrm{mg}$ (with a predicted human $C_{\max }$ of $0.02 \mathrm{nM}$ ) (data on file, RTI). Once again, these concentrations are much less than the lowest observed to cause prolongation of QTc in cynomolgus monkeys (>920 nM).

JDTic activates JNK, which can in turn cause disruption of fatty acid oxidation in a human ventricular-derived cardiomyocyte cell line and cardiac dysfunction in mice, a potential mechanism through which JDTic could cause cardiac dysfunction in humans. However, LY2456302 does not activate JNK (Melief et al, 2011); nevertheless, a single episode of NSVT was observed among 21 subjects (5\%) who received at least one dose of LY2456302 in the first-inhuman study (Lowe et al, 2014). The "5-beat ventricular tachycardia (occurred) approximately $8 \mathrm{~h}$ after a single 25 $\mathrm{mg}$ dose' in one of the eight subjects receiving that dose, but NSVT was not observed in any of the seven subjects receiving a $60-\mathrm{mg}$ dose. The numbers are few, but here NSVT is not dose-related, so again the single episode might be unrelated to the KORAn activity of LY2456302. Still, given its occurrence and the NSVT that have been associated with naloxone, there remains the possibility that a human cardiac response to these agents could be associated more directly with the KOR itself and be a class effect of KORAn rather than specific toxicities associated with the molecules. It simply is impossible to know from the currently available data.

Given the therapeutic potential of the KORAn agents, it is imperative that further preclinical studies using human materials (eg, in vitro experiments with human cardiomyocytes) be conducted to clarify whether there is in fact a human cardiac effect of JDTic or its metabolites; and, if so, the mechanism by which it occurs (ie, class effect or specific JDTic-related toxicity). Depending on these in vitro data, further human trials of JDTic might be considered.

\section{FUNDING AND DISCLOSURE}

RTI International is a registered trademark and a trade name of Research Triangle Institute. RTI International holds the patent on JDTic. This investigation was supported by the National Institute on Drug Abuse (NIDA) grant U19DA021002, for which Dr F Ivy Carroll served as Principal Investigator. JDTic was designed and developed on Dr Carroll's NIDA R01 grant DA09045. Portions of this research were supported by NIDA contracts N01DA-0-8805, N01DA-4-8841, N01DA-8-8880, and the National Institutes of Health Bridging Interventional Development Gaps Program. Mr Jeffrey J Buda was a full-time employee of RTI Health Solutions at the time the study was conducted and in that capacity was also supported by this grant. Dr Thomas R Kosten is the Jay $\mathrm{H}$ Waggoner Chair and Professor of Psychiatry, Pharmacology, Neuroscience and Immunology and Pathology at the Baylor College of Medicine. Dr Dennis Swearingen is an employee of Celerion. Dr Bradford B Walters is a salaried employee of
RTI International, was not supported by the grant, and has no other competing financial interests to disclose.

\section{ACKNOWLEDGEMENTS}

The authors thank Dr Costel Chirila, Dr Ken Rehder, and Dr Laurene Wang-Smith for their assistance throughout the preclinical and clinical investigations. We also very much appreciate the insights of our cardiology colleagues Dr Stephen Leshin, Dr Philip Sager, and Dr Ross Tonkens. And we wish to acknowledge our colleagues at the National Institute on Drug Abuse for their support and suggestions: Dr Jane Acri, Dr Nathan Appel, Dr Nora Chiang, Dr Shwe Gyaw, Dr Richard Hawks, Dr Rik Kline, Dr David McCann, Dr Ivan Montoya, Dr Moo Park, Dr Amrat Patel, Dr Frank Vocci, and Mr Robert Walsh.

\section{REFERENCES}

Ationu A, Sorensen K, Whitehead B, Singer D, Carter N (1993). Ventricular expression and circulating levels of immunoreactive dynorphin in heart transplant recipients. Clin Sci (Lond) 85: 1-4.

Bian JS, Zhang WM, Xia Q, Wong TM (1998). Phospholipase C inhibitors attenuate arrhythmias induced by kappa-receptor stimulation in the isolated rat heart. J Mol Cell Cardiol 30: 2103-2110.

Bjerregaard P (1982). Premature beats in healthy subjects 40-79 years of age. Eur Heart J 3: 493-503.

Brodsky M, Wu D, Denes P, Kanakis C, Rosen KM (1977). Arrhythmias documented by 24 hour continuous electrocardiographic monitoring in 50 male medical students without apparent heart disease. Am J Cardiol 39: 390-395.

Bruchas MR, Chavkin C (2010). Kinase cascades and liganddirected signaling at the kappa opioid receptor. Psychopharmacol 210: 137-147.

Bruchas MR, Yang T, Schreiber S, DeFino M, Kwan SC, Li S et al (2007). Long-acting kappa opioid antagonists disrupt receptor signaling and produce noncompetitive effects by activating c-jun N-terminal kinase. J Biol Chem 282: 29803-29811.

Carroll FI, Carlezon WA Jr (2013). Development of $\kappa$ opioid receptor antagonists. J Med Chem 56: 2178-2195.

Carroll FI, Dolle RE (2014). The discovery and development of the $\mathrm{N}$-substituted trans-3,4-dimethyl-4-(3'-hydroxyphenyl)piperidine class of pure opioid receptor antagonists. Chem Med Chem 9: $1638-1654$.

Clarke JM, Hamer J, Shelton JR, Taylor S, Venning GR (1976). The rhythm of the normal human heart. Lancet 1: 508-512.

Coles JA Jr, Sigg DC, Iaizzo PA (2003). Role of kappa-opioid receptor activation in pharmacological preconditioning of swine. Am J Physiol Heart Circ Physiol 284: H2091-H2099.

Drosatos K, Drosatos-Tampakaki Z, Khan R, Homma S, Schulze PC, Zannis VI et al (2011). Inhibition of c-jun-N-terminal kinase increases cardiac peroxisome proliferator-activated receptor alpha expression and fatty acid oxidation and prevents lipopolysaccharide-induced heart dysfunction. J Biol Chem 286: 36331-36339.

Guo L, Abrams RM, Babiarz JE, Cohen JD, Kameoka S, Sanders MJ et al (2011). Estimating the risk of drug-induced proarrhythmia using human induced pluripotent stem cell-derived cardiomyocytes. Toxicol Sci 123: 281-289.

Hartlage MAG, Theisen MM, de Oliveira NPM, Aken HV, Fobker M, Weber TP (2006). Kappa-opioid receptor antagonism improves recovery from myocardial stunning in chronically instrumented dogs. Anesth Analg 103: 822-832. 
Hinkle LE, Carver ST, Stevens M (1969). The frequency of asymptomatic disturbances of cardiac rhythm and conduction in middle-aged men. Am J Cardiol 24: 629-650.

Hospira (2007). Package insert for Naloxone Hydrochloride Injection, USP. EN-1367. Hospira: Lake Forest, IL, USA.

Hunter R (2005). Ventricular tachycardia following naloxone administration in an illicit drug misuse. J Clin Forensic Med 12: 218-219.

Jaiswal A, Kumar S, Seth S, Dinda AK, Maulik SK (2010). Effect of $\mathrm{U} 50,488 \mathrm{H}$, a $\kappa$-opioid receptor agonist on myocardial $\alpha$ - and $\beta$-myosin heavy chain expression and oxidative stress associated with isoproterenol-induced cardiac hypertrophy in rat. Mol Cell Biochem 345: 213-240.

Jin-Cheng L, Wen Y, Zhao Y, Quan-Yu Z, Shu-Miao Z, Hai-Tao G et al (2008). Anti-arrhythmic effects of kappa-opioid receptor and its changes in ischemia and reperfusion. Arch Med Res 39: 483-488.

Lendeckel U, Muller C, Rocken C, Laube B, Tager M, Huth C et al (2005). Expression of opioid receptor subtypes and their ligands in fibrillating human atria. Pacing Clin Electrophysiol 28(Suppl 1): S275-S279.

Lishmanov AY, Maslov LN, Lasukova TV, Crawford D, Wong TM (2007). Activation of kappa-opioid receptor as a method for prevention of ischemic and reperfusion arrhythmias: role of protein kinase C and K(ATP) channels. Bull Exp Biol Med 143: $187-190$

Liu L, Hu D, Pan X, Lu R, Dan F (2005). Subclass opioid receptors associated with the cardiovascular depression after traumatic shock and the antishock effects of its specific receptor antagonists. Shock 24: 470-475.

Llobell F, Laorden ML (1995). Characterization of the opioid receptor subtypes mediating the negative inotropic effects of DAMGO, DPDPE and U-50,488H in isolated human right atria strips. Neuropeptides 29: 115-119.

Lowe SL, Wong CJ, Witcher J, Gonzales CR, Dickinson GL, Bell RL et al (2014). Safety, tolerability, and pharmacokinetic evaluation of single- and multiple-ascending doses of a novel kappa opioid receptor antagonist LY2456302 and drug interaction with ethanol in healthy subjects. Pharmacokinetics 54: 968-978.

Macallum GE, Houston BJ (1993). Characterization of cardiac alterations in nonsedated cynomolgus monkeys. Am J Vet Res 54: 327-332.

Melief EJ, Miyatake M, Carroll FI, Béguin C, Carlezon WA, Cohen BM et al (2011). Duration of action of a broad range of selective $\kappa$-opioid receptor antagonists is positively correlated with c-jun N-terminal kinase-1 activation. Mol Pharmacol 80: 920-929.

Min SS, Turner JR, Nada A, DiMino TL, Hynie I, Kleiman R et al (2010). Evaluation of ventricular arrhythmias in early clinical pharmacology trials and potential consequences for later development. Am Heart J 159: 716-729.

Peart JN, Gross ER, Gross GJ (2004). Effect of exogenous kappaopioid receptor activation in rat model of myocardial infarction. J Cardiovasc Pharmacol 43: 410-415.

Peng J, Sarkar S, Chang SL (2012). Opioid receptor expression in human brain and peripheral tissues using absolute quantitative real-time RT-PCR. Drug Alcohol Depend 124: 223-228.
Pyle WG, Lester JW, Hofmann PA (2001). Effects of kappa-opioid receptor activation on myocardium. Am J Physiol Heart Circ Physiol 281: H669-H678.

Sobanski P, Krajnik M, Shaqura M, Bloch-Boguslawska E, Schäfer M, Mousa SA (2014). The presence of mu-, delta-, and kappa-opioid receptors in human heart tissue. Heart Vessels 29: 855-863.

Surendra H, Diaz RJ, Harvey K, Tropak M, Callahan J, Hinek A et al (2013). Interaction of $\delta$ and $\kappa$ opioid receptors with adenosine A1 receptors mediates cardioprotection by remote ischemic preconditioning. J Mol Cell Cardiol 60: 142-150.

Thomas JB, Atkinson RN, Vinson NA, Catanzaro JL, Perretta CL, Fix SE et al (2003). Identification of (3R)-7-hydroxy-N-((1S)-1\{[(3R,4R)-4-(3-hydroxyphenyl)-3,4-dimethyl-1-piperidinyl]methyl\}2-methylpropyl)-1,2,3,4-tetrahydro-3-isoquinolinecarboxamide as a novel and potent and selective opioid $\kappa$ receptor antagonist. $J \mathrm{Med}$ Chem 46: 3127-3137.

Tomai F, Crea F, Gaspardone A, Versaci F, Ghini AS, Ferri C et al (1999). Effects of naloxone on myocardial ischemic preconditioning in humans. J Am Col Cardiol 33: 1863-1869.

Ventura C, Spurgeon H, Lakatta EG, Guarnieri C, Capogrossi MC (1992). Kappa and delta opioid receptor stimulation affects cardiac myocytes function and $\mathrm{Ca} 2+$ release from an intracellular pool in myocytes and neurons. Circ Res 7: 66-81.

Xiao GS, Zhou JJ, Cheung YF, Li GR, Wong TM (2003). Effects of $\mathrm{U} 50,488 \mathrm{H}$ on transient outward and ultra-rapid delayed rectifier $\mathrm{K}+$ currents in young human atrial myocytes. Eur J Pharmacol 473: 97-103.

Xiu J, Liu J, Li H, Fu L, Ding D, Han D (2013). The effects of kappaopioid receptor on stretch-induced electrophysiological changes in infarcted rat hearts. Am J Med Sci 345: 129-135.

Yu XC, Wang HX, Pei JM, Wong TM (1999). Anti-arrhythmic effect of kappa-opioid receptor stimulation in the perfused rat heart: involvement of a cAMP-dependent pathway. J Mol Cell Cardiol 31: 1809-1819.

Zatta AJ, Kin H, Yoshishige D, Jiang R, Wang N, Reeves JG et al (2008). Evidence that cardioprotection by postconditioning involves preservation of myocardial opioid content and selective opioid receptor activation. Am J Physiol Heart Circ Physiol 294: H1444-H1451.

Zhou JJ, Pei JM, Wang GY, Wu S, Wang WP, Cho CH et al (2001). Inducible HSP70 mediates delayed cardioprotection in rat ventricular myocytes. Am J Physiol Heart Circ Physiol 281: $\mathrm{H} 40-\mathrm{H} 47$.

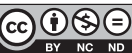

This work is licensed under a Creative Commons Attribution-NonCommercial-NoDerivs 4.0 International License. The images or other third party material in this article are included in the article's Creative Commons license, unless indicated otherwise in the credit line; if the material is not included under the Creative Commons license, users will need to obtain permission from the license holder to reproduce the material. To view a copy of this license, visit http://creativecommons.org/licenses/by-nc-nd/4.0/

Supplementary Information accompanies the paper on the Neuropsychopharmacology website (http://www.nature.com/npp) 